\title{
Neurobiología de la memoria y procesos neuroquímicos implicados
}

\author{
Neurobiology of memory and neurochemical processes involved
}

Marilia Baquerizo Sedano', Jhonatan Astucuri Hidalgo ${ }^{2}$

Universidad Peruana Cayetano Heredia

\section{INTRODUCCIÓN}

Desde el paradigma de la evolución, el aprendizaje y la memoria actúan como medio principal de adaptación de los seres vivos a las modificaciones inciertas del medio ambiente (1), he ahí su importancia. Ambos procesos tienen una relación íntima y a decir verdad, no es posible distinguirlos dentro del circuito neuronal (2). Se asume, sin embargo, con fines académicos, que el aprendizaje es el proceso de adquisición de información y la memoria se refiere a la codificación, almacenamiento y recuperación de esa información aprendida (3). Así también se entiende que el aprendizaje es un cambio relativamente permanente en el sistema nervioso que resulta de la experiencia y que origina a su vez cambios duraderos en la conducta de los organismos; y en contraparte, la memoria es el fenómeno inferido generalmente a partir de esos cambios, que da a nuestras vidas un sentido de continuidad (4).

Dicho sentido de continuidad define nuestra identidad y permite que la información retenida acerca de las experiencias pasadas condicionen las conductas futuras (5). Pero esta información almacenada en el sistema nervioso, no suele formarse de un modo instantáneo y sigue un proceso de formación que incluye al menos dos estadios o etapas subsecuentes: la memoria a corto y largo plazo (1). Es imprescindible hablar un poco de ellas.

La memoria de corto plazo almacena una

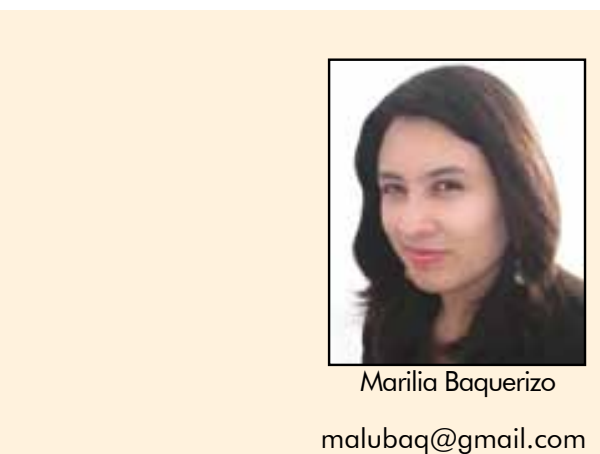

cantidad limitada de información durante un corto periodo de tiempo. Es una memoria inmediata, frágil y transitoria, que se da para los estímulos recientemente percibidos y que resulta bastante vulnerable a cualquier tipo de interferencias (4). Al marcar en el teléfono un número que acabamos de ver en la agenda, no podemos atender más que esa serie de dígitos, sin riesgo de olvidarlos. No obstante, después de hacer uso del número, lo más probable es que lo olvidemos. ¿Cuál es el soporte físico de ese recuerdo? ¿Qué cambios a nivel cerebral lo constituyen?

Por su parte, la memoria a largo plazo almacena una

1 Bach. en Ciencias de la Comunicación, Universidad Nacional del Centro del Perú; Bach. en Psicología, Universidad Continental; pasante en el Laboratorio de Neurociencia y Comportamiento, Universidad Peruana Cayetano Heredia.

2 Estudiante de Psicología, Universidad Continental; terapeuta, Instituto Guestalt de Lima, Perú. 
gran cantidad de información durante un tiempo indefinido. Para diferenciarla de la memoria a corto plazo, se la puede caracterizar como estable, duradera y muy poco vulnerable a las interferencias (4). Es gracias a este tipo de memoria que podemos saber quiénes somos y recordar dónde vivimos, cómo fue nuestra vida pasada, qué conocimientos adquirimos en nuestra preparación universitaria, etc. ¿̇Cómo es que éste tipo de información se almacena durante mucho tiempo en nuestro cerebro? ¿Qué procesos neuronales constituyen ese almacenamiento?

En lo que sigue, se intentará responder a éstas preguntas a partir de una revisión básica del conocimiento científico validado hasta el momento y se describirá con más detalle cómo es que el cerebro, especialmente a través de los mecanismos celulares, alberga un fenómeno humano tan complejo como la memoria.

\section{La materia de la memoria}

Si el número de teléfono, utilizando el ejemplo antes tratado, es de una persona importante para nosotros, a la cual llamamos regularmente, con seguridad lo recordaremos por más tiempo. Ello, porque la carga afectiva y la repetición del estímulo facilitan la reducción del umbral en la neurona, que permite la llegada al núcleo de una cascada de señalización, lo que produce moléculas encargadas de mediar el cambio en la eficacia de las conexiones sinápticas, el crecimiento de nuevas sinapsis o el reforzamiento de las existentes (1).

Dicho de otra forma, la memoria a corto plazo o retención consciente de una información durante un tiempo breve se basa en cambios efímeros, eléctricos - moleculares, en las redes neurales implicadas. Pero, si como consecuencia de la repetición de la experiencia tales cambios persisten, pueden activar la maquinaria anteriormente descrita y dar lugar a síntesis de nuevas proteínas y cambios estructurales. Un diálogo, en definitiva, entre genes y sinapsis (6) denominado proceso de consolidación de la memoria. El resultado es el establecimiento de una memoria a largo plazo basada en cambios estructurales persistentes, como las nuevas espinas dendríticas (7).

Estos cambios se entienden dentro de la denominada plasticidad sináptica que el psicobiólogo canadiense Donald Hebb concibe como: capacidad para modular o cambiar la fuerza de las conexiones entre neuronas, capacidad para cambiar las propiedades y funciones de circuitos neuronales en respuesta a estímulos externos y a la experiencia previa (5). El término, que engloba la realización de varios fenómenos moleculares, permite encontrar respuestas o por lo menos ensayar hipótesis cuando nos preguntamos de qué están hechos los recuerdos.

En 1894, durante una conferencia en la Royal Society, Santiago Ramón y Cajal, padre de la neurociencia moderna y Premio Nobel en Medicina y Fisiología en 1906, enunció una frase que permitiría en nuestros tiempos darle el sustrato celular a la memoria. "El ejercicio mental facilita un mayor desarrollo de las estructuras nerviosas en las partes del cerebro en uso. Así, las conexiones preexistentes entre grupos de células podrían ser reforzadas por la multiplicación de terminales nerviosas..." (5). Casi cincuenta años después, en 1949, Donald Hebb dio una definición más formal de Plasticidad sináptica (antes referida) que textualmente dice en forma de postulado: "Cuando el axón de la célula A excita la célula $B$, y repetidamente o persistentemente interviene en su activación, algún tipo de crecimiento o cambio metabólico tiene lugar en una o ambas células, de suerte que la eficacia de $A$ como una de las célula estimuladoras de B, aumenta" (8).

Es todavía en 1966, que dicho postulado se demostró experimentalmente por primera vez. El noruego Terje Lomo observó que breves trenes de estímulos incrementaban la eficacia de la transmisión en las sinapsis entre la vía perforante y las células granulares de la circunvolución dentada del hipocampo, en conejos anestesiados. 
Unos años después, en 1973 y en el mismo laboratorio, Lomo y el británico Timothy Bliss, descubrieron que una estimulación de frecuencia moderadamente alta en la misma vía producía incrementos estables y duraderos de la respuesta postsináptica, lo que se llamó potenciación a largo plazo (LTP, por sus siglas en inglés) $(9,10)$.

La LTP, que puede definirse como el fenómeno resultante de las alteraciones bioquímicas que causan modificaciones plásticas duraderas, se puede observar en diversas sinapsis por todo el sistema nervioso central, y su acción puede prolongarse durante horas, días o semanas. Algunos trabajos actuales sobre iniciación y mantenimiento de la plasticidad sináptica en el hipocampo muestran como la LTP, artificialmente inducida, produce cambios morfológicos en las espinas dendríticas que podrían constituir la base estructural de la memoria $(4,11)$.

Eric Kandel y su grupo de investigación, al estimular las neuronas del conocido caracol marino Aplysia, también dio cuenta del fenómeno LTP, que el denominó Facilitación a largo plazo -LTF (por sus siglas en inglés). Tanto el LTP como el LTF, parten de la idea de Hebb sobre Plasticidad sináptica, y dan a entender que se dan por la estimulación eléctrica a alta frecuencia de un axón y la siguiente cascada de señalización intracelular hacia el núcleo que tras olas de expresión génica generan cambios a nivel funcional y estructural de la neurona postsináptica (12).

A descripción detallada, pero simplificada, el proceso que acompaña al LTP es el siguiente. En milisegundos, en el marco de una sinapsis, la activación pertinente da lugar a una liberación de glutamato (principal neurotransmisor excitador) desde la neurona presináptica que activa receptores AMPA (alfa-amino-3-hidroxy-5metil-4-isoxazole propionic acid, principal receptor ionotrópico del glutamato) y, en unos segundos más, la despolarización postsináptica lograda en el área, libera a los canales de los receptores de coincidencia asociativa NMDA (N-metil-D- aspartato, principal receptor metabotrópico del glutamato) de los iones $\mathrm{Mg} 2+$ que los bloquean, lo cual permite un gran influjo postsináptico de $\mathrm{Ca} 2+$ a través de los canales de esos receptores y de otros ligados a receptores de glutamato dependientes de voltaje.

Todo ello, a su vez, origina la activación de cinasas (enzimas) que, modulando determinados sustratos, por un lado, inducen cambios en el citoesqueleto de la neurona en el plazo de minutos $y$, por otro, activan factores de trascripción de ARNm y síntesis de proteínas receptoras AMPA, las cuales migran hacia los lugares modificados $y$, en el plazo de horas, se insertan en la membrana y contribuyen a la estabilización de los cambios habidos en el citoesqueleto de la neurona postsináptica. En todo este proceso, es preciso prestar atención a la rapidez (sólo minutos) con la que el aprendizaje es capaz de producir cambios morfológicos en el sistema nervioso $(13,1)$.

Aunque se sabe que los diversos sistemas de memoria (implícita, explícita y de trabajo) requieren la participación de diferentes circuitos neuronales y se localizan en distintas regiones del cerebro; las investigaciones sobre LTP se centran en la región del hipocampo, dada su estructura y organización simples (14), y porque en la actualidad, especialmente gracias a las invetigaciones de Brenda Milner, se sabe que el hipocampo en particular y el lóbulo temporal en general, son componentes imprescindibles para la adquisición de nuevos recuerdos de tipo explícito o declarativo, tanto en humanos como en otros mamíferos (5).

Llegar a encontrar el posible substrato de la memoria explítica no ha sido fácil. Kart Lashley, a principios del siglo XX, realizó numerosos estudios en cerebros de ratas con el objetivo de responder dónde se encuentran los recuerdos, y tras sus estudios concluyó que " la memoria, una vez formada, no reside en ninguna área concreta del cerebro, sino que su magnitud se halla, en cierto modo, condicionada con la cantidad de tejido intacto". (15) 
A partir de ese momento, se ha probado mediante varias técnicas quirúrgicas, farmacológicas y de neuroimagen, que en el cerebro la memoria no está totalmente localizada ni deslocalizada, sino que se constituye en varios conglomerados de circuitos especializados en diversas áreas correspondientes a las distintas funciones cerebrales y los tipos de memoria. Así, los procesos de plasticidad sináptica en la amígdala controlan nuestras respuestas emocionales; y procesos plásticos en el estriado regulan procesos adictivos y algunas formas de aprendizaje procedimental. Por otro lado, las conexiones en la corteza cerebral parecen ser especialmente plásticas, pues el entrenamiento en una nueva habilidad motora provoca un aumento de la áreas de la corteza motora correspondientes; y la estimulación repetida de unos receptores sensoriales da lugar a una expansión progresiva del área de la corteza que responde a la estimulación de esos receptores (5).

\section{CONCLUSIONES}

La memoria es un fenómeno íntimamente relacionado con el aprendizaje, que supone un cambio a nivel comportamental, cognitivo y neuronal. Su proceso de formación incluye al menos dos estadios o etapas subsecuentes: la memoria a corto plazo y la memoria a largo plazo.

La diferencia clave entre estos dos estadíos yace en la persistencia del cambio que producen sobre las conexiones sinápticas. Los conceptos de plasticidad sináptica y potenciación a largo plazo - LTP, explican el soporte neuroquímico de la memoria. Sobre ellos se infiere que el cerebro y sus conexiones cambian anatómica y funcionalmente como producto de la experiencia.

Desde la neurobiología se sabe que en el cerebro la memoria no está totalmente localizada ni deslocalizada, sino que se constituye en varios conglomerados de circuitos especializados en diversas áreas correspondientes a las distintas funciones cerebrales y los tipos o sistemas de memoria. 


\section{REFERENCIAS BIBLIOGRÁFICAS}

1. Morgadol. Psicobiología del aprendizaje y la memoria. CIC, Cuadernos de Información y Comunicación. Madrid: Universidad Complutense de Madrid; 2005. pp. 221-233.

2. Poolton JM. Masters RS, Maxwell JP. The relationship between initial rorless learning conditions and subsequent performance. Hum Mov Sci. 2005; 24 : 362-78.

3. Purves D. y cols. Neurociencia. mericana. 3era edición. Editorial Médica Pana. Madrid; 2007.

4. Morgado I. Psicobiología del aprendizaje y la memoria: fundamentos y avances recientes. Rev Neurol. 2005 40(5): 289-297.

5. Barco A. La materia de los recuerdos curcuitos neuronales y cascadas moleculares. Rev Mente y Cerebro. 2010: 40.

6. Kandel E. The molecular biology of memory storage: a dialogue between genes and synapses. Science, vol. 294, págs. 1030-1038; 2001.

7. Engert F, Bonhoeffer. Dendritic spine change associated with hippocampal. long-term synaptic plasticity. Nature. 1999; 399: 66-70.

8. Hebb D. Organización de la conducta. 1985. Tomás del Amo Martín, Trad. Madrid: Debate. (Trabajo original publicado en 1949, The organization of behavior: A neuropsychological theory. New York: Wiley).

9. Bliss TV, Lomo T. Long-lasting potentiation of synaptic transmission in the dentate area of the anaesthetized rabbit following stimulation of the perforant path. J Physiol. 1973; 232(2):331-356.

10. Lomo T. The discovery of long-term potentiation. Philos Trans R Soc Lond B Biol Sci. 2003; 358(1432): 617-620.

11. O'Keefe, John \& Nadel, Lynn. The hippocampus as a cognitive map. Oxford University Press; 1978.
12. Kandel E., Schwartz J., Jessel T. Principios de Neurociencia. cuarta edición. Madrid: McGraw-Hill; 2001. p. 1227-1247.

13. Lamprecht R, LeDoux J. Structural platicity and memory. Nat Rev Neurosci 2004; 5( ) 45-54.

14. Squire L, Kandel E. Memory: from mind to molecules. Owl Books, 2000.

15. Kandel E. En busca de la memoria: el nacimiento de una nueva ciencia de la mente. Katz editores. 2007. 